\title{
Adeus, cavalo, de Nuno Ramos: quando o corpo vibra e o texto estremece um ato de leitura
}

\author{
Irma Caputo*
}

\section{Introdução: se ler é viver}

A ideia do presente artigo é apresentar um ato de leitura pessoal partindo de um texto literário que permite trabalhar os conceitos de especificidade, voz, performatividade e indeterminação. ${ }^{1} \mathrm{O}$ texto selecionado para o ato de leitura é Adeus, cavalo (2017), do escritor e artista plástico Nuno Ramos. A ideia de ato de leitura ${ }^{2}$ vem da necessidade de uma reapropriação da prática de leitura como processo ativo e não passivo.

Além das interpretações dos textos oferecidas pelas inúmeras bibliografias primárias, secundárias, ensaios etc., cada leitura representa a construção de um universo particular e único dos outros leitores e até mesmo das suas leituras anteriores. A esse respeito, Paul Zumthor (2007, [199o], ${ }^{3}$ p. 54) comenta: "Amanhã retomando o mesmo texto eu acharei outro". Já Susan Sontag, no famoso ensaio "Contra a interpretação" (1987, [1964]), convidava a voltar a uma erótica das artes e ao não fechamento no labirinto da hermenêutica.

Se a minha própria leitura amanhã pode ser outra, como é possível defender a imanência dos significados impressos em algumas obras pelos arcontes da mimesis? Parafraseando, ou melhor, recolocando o Derrida de outro texto ("Mal d'archive, une impression freudienne", 2001, [1995]), poder-se-ia afirmar que há arquivos conflitantes: o meu arquivo como leitor, que conduziria minha experiência do texto para uma certa direção; e o dos arcontes ${ }^{4}$, os quais enredam a interpre-

* Doutoranda em Estudos da Linguagem, na PUC - Rio de Janeiro, RJ, Brasil. E-mail: irma.caputo@gmail.com.

1 O presente trabalho foi realizado com o apoio da Coordenação de Aperfeiçoamento de Pessoal de Nível Superior - Brasil (Capes) - Código de Financiamento oo1.

2 Essa expressão foi objeto de estudo e pesquisa durante a disciplina "Teoria da interpretação", ministrada pela professora Helena Martins da PUC - Rio de Janeiro em teoria da interpretação.

3 A primeira vez que será citada a obra de um autor, comparecerá o ano de publicação da edição usada e em seguida o ano de primeira publicação, nas demais citações só constará o ano da edição usada para o artigo.

4 Em "Mal d'Archive" Derrida, ao falar de arquivo, explica como eram organizados os mesmos na Grécia Antiga. Os arcontes, ou seja, os juízes, mantinham todos os documentos importantes fun- 
tação de uma obra segundo regras canônicas, segundo uma História, grande narração que apaga toda a linha de fuga. Aliás, se as nossas leituras estão sujeitas ao aqui e agora, parecem injustificadas algumas pretensões da crítica que imprimem nos textos interpretações cristalizadas no tempo, numa espécie de coerção que conduz a um discurso específico único, unívoco e unificador, ou seja, a um mesmo.

Na conferência proferida em 1970 para a aula inaugural no Collège de France, conhecida como "A ordem do discurso", Michel Foucault salienta a importância de o leitor abandonar a "vontade de verdade" (2016, p. 19), a qual consistiria na busca de uma mensagem imanente e transparente do texto:

Enfim, creio que essa vontade de verdade assim apoiada sobre um suporte e uma distribuição institucional, tende a exercer sobre os outros discursos - estou sempre falando de nossa sociedade - uma espécie de pressão e como que um poder de coerção. Penso na maneira como a literatura ocidental teve de buscar apoio, durante séculos, no natural, no verossímil, na sinceridade, na ciência também - em suma, no discurso verdadeiro.

Essas fossilizações críticas, que orientam a leitura, parecem provir principalmente de uma ideia de autor como antecedente a todo o texto (BARTHEs, 2015, [1984], p. 66). Os críticos, na realidade, interpretam a partir de um suposto sentido que o autor teria imprimido no texto, como se o escritor fosse o passado de sua própria obra (BARTHES, 2015, p. 66). Assim, nos diferentes vieses e implicações metodológicas, nasce uma escola do interpretar que se torna praticamente uma compulsão. Identificar o autor como força centrípeta a partir da qual interpretase uma obra como sua direta emanação pode acarretar vários problemas.

O primeiro deles estaria ligado à "biografização" da interpretação do texto. Será que todo o texto é um reflexo da biografia do autor? Será que um excesso de associação entre dados biográficos e significado da obra não levaria a enganos maiores? No ensaio "Écrire la lecture" (2015), Barthes dá uma advertência: uma leitura vrai (verdadeira) admite o direito à folia, mas não ao delírio. Por leitura verdadeira ele não entende uma interpretação certa ou verdadeira no sentido de estabelecer com certeza um único significado possível, mas sim uma leitura original, genuína, capaz de deslindar as multiplicidades de referências de um texto e as diferentes veredas de abordagem possíveis. Assim, muitas vezes um excesso de correlação entre biografia do autor e obra leva a interpretações delirantes.

O segundo problema seria uma invariável recondução da obra ao pensamento do autor, o que pode engessar a leitura dela em paradigmas que impedem conexões por vezes mais abrangentes.

dantes da lei ou úteis ao funcionamento da justiça arquivados em suas próprias residências. Portanto, só os documentos julgados fundamentais pelos mesmos arcontes/juízes eram preservados, eram eles os responsáveis pela edição do arquivo (DERRIDA, p. 8, 2001). 
Por último, o peso do autor, que se presume demiurgicamente imprimir um sentido e uma intenção no escrito, leva à atitude quase maníaca de alcançar alguma significação nuclear do texto. A busca de uma mensagem-cerne traz uma outra questão, a de quão enraizada está uma visão essencialista de linguagem como representação binária.

A grande relevância conferida à figura do autor, com todas as consequências ligadas à interpretação e à superinterpretação, é, segundo Barthes (2015, p. 68) uma necessidade da modernidade que prestigiaria o indivíduo até as últimas consequências. Umberto Eco, na perspectiva do semiólogo, também já havia ironizado sobre a mania de superinterpretar (1993). Do mesmo modo, Susan Sontag (1987, p. 17) comenta que a interpretação: "Na realidade, é $a$ forma moderna de compreender algo e aplica-se a obras de qualquer categoria", englobando todo o sentido do texto em esquemas de entendimento e representação racional e se esquecendo da livre fruição da obra.

Postula-se, portanto, a necessidade de recuperar uma relação direta com o texto, consagrando de maneira definitiva a morte do autor (BARTHES, 2015), liberando finalmente a leitura das interpretações cristalizadas pela crítica e das interpretações preconcebidas, assim como lembra Susan Sontag (1987, p. 17), mencionando Lawrence: "Jamais acredite no narrador, acredite na história".

Se depois entrarmos na diatribe sobre o que é linguagem, adotando o ponto de vista de uma linguagem como forma de vida, como performance, pode-se afirmar que o texto se vive. Porém se adotarmos uma visão de linguagem como sistema de representação, o texto é recebido e se decodifica através do deslindamento dos signos mais ou menos transparentes, e sua recepção seria também mediada por um discurso sobre a paternidade da obra.

$\mathrm{Na}$ diatribe sobre a interpretação, ao adotar qualquer tipo de posição sobre a linguagem, nos três caminhos possíveis identificados por Helena Martins (2001) - os quais podem ser (i) realista, (ii) mentalista e (iii) pragmatista - existiriam alguns problemas ligados à estrutura binária da representação, que só mudaria entre os três para rede de referências (i) coisas reais do mundo, (ii) ideias mentais, (iii) contextos situacionais. Desbravando assim a selva dessa discussão, Helena Martins (2001, p. 444) mostra os limites de cada um destes caminhos:

1. caminho realista: a linguagem como mimesis/realidade é uma mera redução simplista, pois já está mais do que provado que as correspondências biunívocas são pouco sustentáveis; não existe uma correspondência perfeita entre cada palavra e os elementos do mundo existente;

2. caminho mentalista: a linguagem como correspondências de entidades mentais compartilhadas, também criaria problemas ao depararmos com conceitos nem tão complexos, como, por exemplo, o de "cachorro". De fato, usando um exemplo da autora, como essa palavra chegaria a conter a ideia de labrador e poodle ao mesmo tempo?; 
3. caminho pragmatista: o pragmatismo, que dá valor a uma palavra a partir do contexto de uso, também levaria a certos dilemas, tal como "explicar como é possível identificarmos uma palavra com a mesma em diferentes situações, face de sua irredutível e em última instância não inventariável multiplicidade de usos".

É preciso, portanto, ao adotar uma ideia de leitura como vivência, também questionar a ideia de essência da linguagem. É preciso, enfim, rediscutir o que é linguagem. Esse ato de leitura é uma tentativa de afastamento de uma linguagem concebida como mimesis, seja como representação pura do mundo no sentido referencial (sensível), seja como representação do mundo no sentido de revelação (extrassensível), ${ }^{5}$ através da interpretação dos signos. O entendimento da linguagem como representação referencial pura do mundo remontaria a antes de Babel, quando os nomes pousavam sobre as coisas à medida que Adão ia nomeando-as, aderindo perfeitamente a elas. Os nomes eram, nesse caso, a equivalência perfeita das coisas às quais se referiam. Enquanto segunda vertente, a representação como interpretação, desenvolver-se-ia a partir do século XVI, quando "considerava-se que os signos tinham sido depositados sobre as coisas para que os homens pudessem desvendar seus segredos, sua natureza ou suas virtudes" (FoucAUlt, 2016, [1966], p. 81). As palavras precisariam de interpretação, pois a equivalência a partir desse momento não seria mais manifesta. Em ambos os casos a linguagem é entendida como representação; no caso referencial, é transparente, porque o significado é dado por associação direta; no caso da revelação é opaca, porque o significado não é dado por associação direta, mas é mediado pelo trabalho hermenêutico. Durante a Renascença ainda não se concebia o fragmento como elemento constitutivo da linguagem e a opacidade só existia como degrau anterior de uma transparência almejada, a qual se chegaria através do trabalho interpretativo.

Opta-se, nesse ato de leitura, tomando distância das posições acima expostas, por pensar na linguagem como algo a ser constantemente negociado na sua deferibilidade, instantaneidade e perecibilidade, algo que se vive no aqui e agora.

A fim de estimular esse ato de leitura e a reflexão das questões aqui problematizadas, partimos de algumas perguntas postas por Foucault:

É bem possível que todas as questões que atravessam atualmente nossa curiosidade (Que é linguagem? Que é um signo? O que é mudo no mundo, nos nossos gestos, em todo o brasão enigmático de nossas condutas, em nossos sonhos e em nossas doenças - tudo isso fala, e que a linguagem

5 Por linguagem como representação do mundo no sentido de revelar o extrassensível entende-se o princípio da analogia, o qual em várias épocas tem dominado a organização do saber, como no Renascimento (FoucAulT, 2016, [1966]). A linguagem diz algo enigmático que tem que ser entendido também graças à intervenção de outros símbolos e imagens de comparação associativa. Por exemplo se X quer dizer Y e existe uma semelhança entre $\mathrm{Y}$ e $\mathrm{B}$, então também haverá uma conexão entre o que dizem X e B. Esse procedimento, em termos de construção de cadeias associativas, muitas vezes também é usado pela hermenêutica. 
sustenta, segundo que gramática? Tudo é significante, ou o que o é, e para quem, segundo que regras? Que relação há entre a linguagem e o ser, e é realmente ao ser que sempre se endereça, pelo menos aquela que fala verdadeiramente? Que é, pois, essa linguagem que nada diz, jamais se cala e se chama "literatura"?) - é bem possível que todas essas questões se coloquem hoje na distância jamais superada entre a questão de Nietzsche e a resposta que lhe deu Mallarmé (Foucault, 2016, p. 422).

A literatura como contradiscurso, portanto, nada diz, mas jamais se cala. Ela de alguma forma sobressai às regras discursivas paradigmáticas e agindo esteticamente sobre a linguagem, como forma expressiva, ativa novos processos de relação do leitor com o texto, onde o significado não é dado segundo regras de unidades discursivas, mas há que ser constantemente construído.

Partindo da ideia de que não há imanência na linguagem, não pode haver imanência em um texto, ainda mais se se trata de um texto literário contradiscursivo. Esse ato de leitura reivindica, portanto, um papel ativo do leitor e o ato de ler como energheia ( $\dot{\varepsilon} v \dot{\varepsilon} \rho \gamma \varepsilon l \alpha$ ), uma força em ação, em contratendência a uma ideia de leitura como dunamis ( $\delta \dot{v} v \alpha u \iota \varsigma$ ), ou força em potência. ${ }^{6}$

A ideia da leitura como energheia estaria ligada a uma visão da linguagem como algo vivo, que não precisa de uma finalização enteléquia ( $\dot{\varepsilon} v \tau \varepsilon \lambda \dot{\varepsilon} \chi \varepsilon l \alpha)$, ou seja, de uma síntese discursiva que estabeleça algum significado final segundo alguma gramática do mundo. Essa leitura aberta, sem finalização, parte de uma ideia de texto como experiência, em que o próprio corpo-leitor é chamado em causa junto com todos os sentidos para a construção do processo de significação. Eis também o porquê da escolha de um texto performático como Adeus, cavalo (2017).

Por outro lado, o contraponto da leitura como dunamis estaria ligada a uma certa passividade, e a linguagem, nesse caso, seria vivida só em potência, na sua função referencial sensível ou extrassensível, em que o único corpo chamado em causa seria o do autor "originário" e dos críticos que fundaram arconticamente as interpretações. Ler o texto em potência, como dunamis, implica lê-lo por aquilo que o mesmo poderia dizer segundo uma lógica binária ou de arqueologia hermenêutica e não por aquilo que faz sentir e desperta no corpo-leitor.

Por isso, opta-se por uma leitura como energheia, por viver o texto com o próprio corpo-leitor e vivenciar dentro de si os outros corpos que emergem no processo de significação. Abandona-se definitivamente a leitura como dunamis que aborda o texto como impressão, recebendo o reflexo de outros corpos, os que fizeram a "crítica" e os que deram origem à obra, em um processo que faz a violência do arquivo ${ }^{7}$ oficial imprimir-se nas nossas leituras.

\footnotetext{
6 Os conceitos de energheia e dunamis como força em ação e força em potência, são caros a filosofia grega, especialmente a Aristóteles. A associação desses mesmos conceitos ao ato de leitura é uma liberdade da autora do presente artigo.

7 A expressão "violência do arquivo" é tomada emprestada de Derrida em Mal d'archive, une impressione freudienne (2001).
} 
Resumindo o presente ato de leitura:

- configura-se como energheia, força em ação; ${ }^{8}$

- não considera o autor como anterior ao texto, mas entra a fazer parte da vivência do texto; o leitor experimenta o autor dentro do texto, através dos procedimentos estéticos escolhidos, mas não experimenta o texto dentro de uma suposta intencionalidade do autor e de significados impressos pela crítica;

- se a linguagem não é referência sensível ou extrassensível, a leitura não é uma associação ou interpretação, mas uma vivência/experiência; há nela a participação do corpo, que não é necessariamente materialidade, mas o apelo aos sentidos no ato de significação do texto;

- satisfaz um desejo de impertinência (BARTHEs, 2015, p. 40), um elã de perversão;

- será experimentado à maneira apontada por Roland Barthes em "A morte do autor”, ou seja, como uma camada de múltiplas escrituras (BARTHEs, 2015, p. 40) cuja unidade não reside na origem, mas no destinatário; o que não possui histórias ou leituras prévias, como um vinil virgem, cujas impressões serão gravadas ao vivenciar o texto.

\section{Adeus, Cavalo: especificidade ou indeterminação?}

O livro escolhido configura-se - dentro das dimensões contemporâneas do estético - como um desafio a qualquer tipificação de gênero textual. Já faz tempo que se discute a implosão das antigas categorias e gêneros textuais, fala-se em crise do romance, de prosa poética ou fim do verso, dependendo da perspectiva. Há quem diga que a quebra do enjambement marque o fim da poesia (AgAmBEN, 1995) ou que há textos que não são literaturas, estabelecendo hierarquias entre tipologias textuais. Há uma mudança que envolve novas formas expressivas da linguagem verbal, formas estas que se derramam em outras artes, numa contaminação de práticas que se servem de suportes distintos e múltiplos.

\footnotetext{
8 A tal propósito, apesar de não ser radical na sua posição de semiólogo, pois no mesmo texto faz apelo a uma leitura livre, mas sem delírios, parece interessante citar essa passagem de Barthes: “Ceci est pour indiquer qu'on ne peut raisonnablement espérer une Science de la lecture, une Sémiologie de la lecture, à moins de concevoir qu'un jour soit possible - contradiction dans les termes - une Science de l'Inépuisement, du Déplacement infini: la lecture, c'est précisément cette énergie, cette action qui va saisir dans ce texte, dans ce livre, cela même 'qui ne se laisse pas épuiser par les catégories de la Poétique'; la lecture, ce serait en somme l'hémorragie permanente, par où la structure - patiemment et utilement décrite par l'Analyse structurale - s'écroulerait, s'ouvrirait, se perdrait, conforme en cela à tout système logique qu'en définitive rien ne peut fermer - laissant intact ce qu'il faut bien appeler le mouvement du sujet et de l'histoire: la lecture, ce serait là où la structure s'affole" (BARTHES, 2015, p. 48).
} 
Os limites que definiam a tipificação textual parecem ser borrados por produções literárias que encarnam a ideia de linguagem como forma de vida, que quebram com as regras aristotélicas de encadeamento cronológico ou de relações de causa-efeito dos fatos, vindo a apresentar novas formas de montagem. Seria suficiente pensar em Eles eram muito cavalos, de Luiz Ruffato (2001), obra na qual a fluidez da vida contemporânea se desdobra em um texto que resulta numa montagem de imagens, cuja sintaxe está completamente subvertida: a desordem e a histeria urbana são o próprio texto. A escrita incorpora lógicas da fotografia como resultante de um conjunto de instantâneas. Outro texto emblemático é Delírio de Damasco (2012), de Veronica Stigger, composto por frases captadas em conversas de rua, e que se tornou primeiro uma exposição em painéis de cobertura de obras de metrô da cidade de São Paulo, para num segundo momento converter-se em livro. Delírio de Damasco poderia bem ser definido, segundo a acepção Graziela Speranza, como texto instalação (2012). O texto vem da rua, portanto é pura performance e, ao mesmo tempo, usa suportes distintos como painéis e papel. O papel se contamina e absorve a prática figurativa do painel: uma frase em cada página.

Nuno Ramos, artista plástico que já publicava textos literários desde 1993, alcançou fama como escritor em 2011, ao ser agraciado com o prêmio Portugal Telecom de Literatura pelo livro Ó (2008). Os primeiros textos, especialmente "Cujo" (1993), resultam de uma junção de fragmentos de vida heterogêneos, alguns dos quais são relatos, às vezes poéticos, às vezes técnicos, de sua própria produção como artista plástico, o que Eduardo de Oliveira (2018) definiu como "semantização dos processos artísticos" (p. 16) ou "prosa de ateliê" (MAssi apud Oliveira, p. 15):

Pus todos juntos: água, alga, lama, numa poça vertical como uma escultura, costurada por seu próprio peso. Pedaços do mundo (palavras principalmente) refletiam-se ali e a cor dourada desses reflexos dava uma impressão intocada de realidade. O som horrível de uma serra saía de dentro da poça e completava o ritual, como uma promessa (pela qual eu esperava, atento) que fosse conhecimento e revelação. Foi então, como se suasse, que algumas gotas apareceram em sua superfície e escorreram, primeiro lentas e depois aos goles, numa asfixia movediça que trouxe o interior à superfície e desfez em pedaços a suspensão e a paralisia. E feita sujeira, aos meus pés, era um lamento do que tinha visto e perdido.

Pus o vidro derretido sobre o breu, que dava forma côncava ao feltro. O problema era o que fazer com o vidro agora, já que se ele prevalecesse eu teria uma escultura de vidro. Bem, poderia derretê-lo novamente, ou lançar asfalto frio para recobri-lo, mas neste caso teria uma escultura de asfalto frio. Seria preciso, então, que os materiais se transformassem uns nos outros ininterruptamente e, o que é mais difícil, encontrar um nome para este material proteico, um nome que tivesse as mesmas propriedades dele.

Pôr um nome dentro de uma pedra não faz sentido, pois ela já tem este nome, pedra (RAMOS, 1993, pp. 9-11). 
Como pode se notar nessa longa citação, a performance do autor como artista adentra o texto; a própria leitura é o fazer-se do texto, não há mais produto, mas processo, e a leitura faz parte dele. Eis que a energheia ganha terreno, o leitor também é chamado a performar, já que a sua própria leitura acompanha o processo relatado para a construção da obra de arte plástica. O corpo-leitor sente a consistência dos materiais e participa das dificuldades de junção dos díspares que o autor vive: o deslize da forma, o tropeço da matéria. Nos primeiros textos de Nuno Ramos a performatividade é dada pelos relatos dos processos do ateliê, os quais se refletem também na escrita praticada: a justaposição com borramentos de fronteiras, ou colagem sem bordas, para parafraseá-lo em entrevista inédita (abril de 2017).

Agora, em Adeus, cavalo, a performatividade parece ser dada pelo elemento teatral e pela voz, presente de formas distintas. Mas antes de entrar em uma análise mais detalhada da obra, tentar-se-á resumir o que se percebe ao ler o texto e surge uma primeira pergunta: pode-se dizer que há narração? Antes de articular qualquer resposta, oferece-se a experiência dessa escrita através da seleção de trechos que possam encarnar uma possível chave em forma viva:

Sou eu o pagante, agora. Que palavra! Um peixe carnudo na água fria, já disse isso? O mizão do violão do Nelson Cavaquinho. Uma voz, todas elas. Um cavalo. Eu podia encená-los. Esfria isso. Vou ler para você (RAmos, 2017, p. 13). ${ }^{9}$

Agora a voz já não era bem minha. CAVALO MONTANHA-RUSSA

Um rouxinol. Um poente. Eu disse que sou um poente. Um quê?, perguntaram em coro. Um disco riscado. Sou o portador de uma cor, mais exatamente (RAmos, 2017, p. 14).

Como é possível notar nesses trechos, Nuno Ramos, em Adeus, cavalo, leva às últimas consequências as escolhas estilísticas já presentes de forma menos radical em textos anteriores. Se por narração se entende uma concatenação, ou seja, uma sequência de eventos à maneira aristotélica, aqui parece não haver narração, visto que não há uma sequência de fatos: o texto e a linguagem são pura performance. $\mathrm{O}$ pano de fundo de todo o livro é uma entrevista a um ator de teatro, que incorpora várias vozes, exatamente como se ele, de repente, fosse puxado por um cavalo selvagem que o levaria a habitar as vozes das personagens que o atravessam. Nessa comunhão de relatos e diálogos que se cruzam e entrecruzam, com um público passivo que só reivindica o seu papel de pagante, destacam-se quatro vozes principais: a do ator que incorpora as vozes, a de Procópio (refere-se ao ator Procópio Ferreira, 1898-1979), a de Nelson Cavaquinho (1911-1986) e a de Giuseppe Ungaretti (1888-1970); os quais discutem os mais variados assuntos entre eles o papel do artista e sua relação com o público. A voz do ator, às vezes, aparece misturada à voz de Procópio, que também é ator.

\footnotetext{
9 A partir desse momento todas as citações de Adeus, cavalo em que aparecerem grifos, é porque
} no original aparecem dessa forma. 
Essa mistura de vozes é enfatizada e por vezes dificultada pela diferença de layout na escrita, cuja organização não aparece uniforme no suporte de papel. De fato, as mudanças de caráter e os grifos (particularmente o itálico e o uso da caixa alta) sugerem leituras múltiplas e cruzadas. Uma escrita em itálico pode ser atravessada por uma rubrica ou por uma frase com caráter regular, pulando a qual pode ser restituída unidade da voz do itálico. Às vezes, como no caso da primeira citação, o mesmo caráter ou grifo pode indicar o continuum de vozes diferentes. Parece haver, portanto, uma reiteração de padrões que podem ser renegociados a cada capítulo. As vozes se cruzam e se confundem, é preciso voltar ao texto, ler e reler, já que o mesmo não se oferece fácil:

Fala baixo e para dentro, mas com uma impostação tão perfeita que todos parecem compreender.

O bege dessa fórmica.

(gesto lento e majestoso)

sou eu. Tenho a voz de um cavalo. CAVALO CONTINÊNCIA.

Minha garganta é cheia de rosas. E muco. Ouça: vou contar. Mas fora, completamente fora

(gesto, apontando as coisas ao seu redor)

do tablado. Que palavra! Não digo nada ali. Nunca mais.

Eu, o mizão de Nelson Cavaquinho. Uns restos de tabaco. Moedas. Uns restos de umas pétalas no bolso. Calma. OK.

Mas é isso.

(pausa)

É isso. Os restos de um coro. Ouça, amigo. Pedaço de um caniço CAVALO TROLOLÓ

$[\ldots]$

olhando as ok, estrelas. Vá para casa. Não posso. Me toque. Não posso. Então não faça mais nada (RAmos, 2017, p. 10-11).

A ecleticidade do texto é evidente: às vozes misturam-se as indicações que geralmente são dadas nas rubricas teatrais - (gesto, apontando as coisas ao seu redor), por exemplo -, mas que ao mesmo tempo poderiam ser simples descrições extemporâneas de uma cena por uma voz ou os pensamentos calados do ator. Há uma colagem de estilos, situações, assuntos e personagens e o que se lê parece estar próximo de um texto teatral, ainda sem sê-lo por completo, pois também aparece o plafond da entrevista (em forma mais nítida no final do livro) como uma espécie de teatro no teatro; no fundo a entrevista também é uma forma de performance. Participam da entrevista/espetáculo, que se articulam como incorporações de vozes pelo ator principal, personagens importantes interagindo entre si e dando lições 
de vida. Eventos costurados sem uma lógica aparente se intercalam: há a morte de Procópio e seu funeral, a inauguração da ponte Rio-Niterói em 1974, momento em que Ungaretti caminhará sobre as águas como Jesus Cristo, como a miragem de um milagre. Percebe-se uma certa vontade de colocar a vida assim como ela é - múltipla, confusa, em transição contínua - na escrita. A cada passo o leitor encontra estilos, personagens, práticas discursivas diferente, sendo obrigado a renegociar a própria postura perante o texto. Em seus primeiros livros, Cujo (1993) e $O$ pão do corvo (2001), Nuno Ramos questiona o poder de representação das palavras e da linguagem como ferramenta (in)capaz de representar as camadas sensoriais que oferece a matéria, assim como para compensar esse descompasso perfura o papel através do relato do processo de produção das obras de artes plásticas e através do relato da matéria viva em transformação - como se o processo, antes que o produto, fosse a própria performance.

Em Adeus, cavalo são a teatralidade, o corpo do ator principal e as vozes que incorpora que afirmam presença, conferindo ao texto essa sensação de vida. Uma voz que vira murmúrio, um barulho constante, aquele "rumor da língua" (BARTHES, 2015), que irrita e desperta ao mesmo tempo, um barulho que não pode ser ignorado.

Pensando em livros distintos do mesmo autor, e em sequência cronológica do mais antigo ao mais recente, pode-se marcar uma trajetória da forma como o autor consegue imprimir através de procedimentos e escolhas estéticas um caráter vivo à sua escrita.

Portanto, do mesmo jeito que o leitor em um livro como Cujo (1993) constrói o sentido do texto acompanhando, a medida que lê, o processo de produção artística como no exemplo que segue:

Quando a água tornou-se chumbo afinal, este processo de evaporação/liquefação interrompeu-se. À minha frente, disforme, um espelho irregular, mas tão nítido, lançava seus reflexos para todos os lados (RAMOS, 1993, p. 11).

e que em um livro como $O$ (2008) acompanha as transformações da matéria em movimento, como no trecho abaixo:

Mas talvez a morte comece, para os que ficam, um pouco antes dessa estranha euforia que há no luto - pelo próprio corpo morto, pela desintegração monstruosa do que foi amado e respeitado. Este é o fato primeiro e eloqüente da morte, a transformação do corpo numa bomba-relógio feita de decomposição e mau cheiro (RAMOs, 2008, p. 39).

Em Adeus, cavalo, a dimensão dinâmica é dada por uma leitura que cria sentido quase como "assistindo" ao desenvolvimento da entrevista/espectáculo/bate-papo 
cruzados dos personagens. A leitura torna-se puro fluxo, o corpo do leitor vive através da voz e do corpo dos outros, estremece com os atores e acompanha as vozes que os possuem com mudanças repentinas. O leitor tem que estar sempre alerta para acompanhar um fluxo pouco linear, é obrigado a manter sua percepção aguçada, ele também se torna ator.

Assim, a leitura torna-se lugar de encontro de várias solidões:

A totalidade das luzes sobre uma única pessoa. A totalidade dos olhos sobre um único corpo. O descompasso entre aquela solidão exposta e a confraria medrosa de nossos olhares (RAMOs, 2017, p. 23).

A teatralidade recriada através da solidão do corpo do ator exposto à multidão dos olhares do público, desdobra-se na relação com o leitor. A solidão do leitor, com sua leitura silenciosa, é desafiada pela invasão da pluralidade de vozes que atravessam o livro, e que o ator incorpora (CAVALO TROLOLÓ, CAVALO MONTANHA, CAVALO MULTIDÃO, CAVALO JABUTI, CAVALO SILOGISMO), e a performance é invertida ou simplesmente desdobrada e recíproca. O leitor não pode fugir do diálogo com essa pluralidade de vozes, que o obrigam a vivenciar estados que oscilam entre a euforia e depressão. A leitura torna-se energheia, já que há performance dentro e fora do livro. Em Adeus, cavalo, os fragmentos de vida entram, de formas distintas, prepotentemente no texto: a dor de Ungaretti com Antonietto, "um bloco de cantores congelado em videotapes e fitas de celulose" (RAMOs, 2017, p. 44), e ainda "galinhas ciscando pela casa, e latas de cerveja e crianças bêbadas de sono e de maus-tratos" (RAMOs, 2017, p. 43). Mas como sintetizar essa disparidade de elementos numa operação estética? Poder-se-ia dizer, à maneira de Rancière, que se vê aqui uma nova forma de montagem: a frase-imagem. Para explicar o que seria a frase-imagem, Rancière aponta para Histoire(s) do cinema, de Godard (1988), que se configura como um conjunto de apropriações cuja montagem consegue construir novas redes de experiências e significações para quem olha. Imagens de Brigitte Bardot e Foucault dando aula no mesmo filme obrigam o "espectador emancipado" (RANCIÈRE, 2006) a cumprir e assumir um papel ativo, o suposto sentido da obra não se oferece na forma de uma resposta/conteúdo visível e extraível do próprio filme, mas se coloca como um processo a ser desenvolvido por quem olha na relação perceptiva:

O cinema que nos conta aparece como uma série de apropriações de outras artes. E ele o apresenta num entrelace de palavras, frases e textos, pinturas metamorfoseadas, planos cinematográficos misturados com fotografias ou fitas de cinejornal, eventualmente ligadas por citações musicais. Em suma, História(s) do cinema é inteiramente tecida com essas "pseudometamorfoses", com essas imitações de uma arte por outra, que recusa a pureza vanguardista. E, nesse amaranhado, a própria noção de imagem, a despeito das declarações iconolundas de Godard, aparece como aquela 
que tem uma operatividade metamórfica, que atravessa as fronteiras das artes e denega a especificidade dos materiais (RANCIÈRE, 2014, p. 52).

Essa nova montagem, frase imagem, ou grande parataxe - através da expansão dos suportes, as apropriações dos discursos, a contaminação de práticas discursivas - monta uma nova forma expressiva, que, para ser válida, segundo Rancière (2014, [2003], p. 58), deve fugir tanto da enumeração esquizofrênica, quanto do "embrutecimento consensual" sujeito às leis do capital. A frase-imagem desconstruindo toda a lógica narrativa (a relação entre o dizível e o visível), diz mostrando e mostra dizendo estabelecendo novas relações perceptivas com o espectador.

De outra perspectiva, Florencia Garramuño (2014) chama essas novas práticas expressivas como poderosas formas do não pertencimento ou arte inespecífica: a ideia de uma especificidade unificadora e englobadora desmorona. Categorias como gênero e a busca de estruturas narrativas não são mais suficientes para articular e mediar a relação do leitor com um texto que se configura como experiência. Todavia, a ideia de Florencia Garramuño de arte inespecífica parece convencer só parcialmente, pois a inespecificidade é um conceito transversal a muitas obras e aplicável em vários contextos, mas pouco diz acerca dos discursos que a mistura de práticas estéticas usadas envolvem e instauram.

A ideia de frase-imagem de Rancière, por outro lado, até colocando em xeque a ideia de medida comum, propondo uma nova medida que seria uma desmedida, deixa claro que as montagens híbridas fora dos paradigmas estéticos habituais inscrevem novos discursos que obrigam o público fruidor a um papel de negociador e construtor de significados/sentidos. Essas produções artísticas, segundo essa montagem, colocam-se fora das categorizações kantianas, da dialética hegeliana, das dualidades platônicas e de uma férrea metodologia cartesiana, só para citar algumas amarrações quem vêm influenciando há muito a forma com que o mundo ocidental produz e interage com as produções artísticas.

Pode-se, portanto, ainda falar de interpretação visto que boa parte da teoria da interpretação baseia-se em categorizações prefiguradas que novas formas expressivas como Adeus, cavalo fogem sem parar? Sujeito e objeto parecem ser um só, a partir do momento em que o teatro está no livro e derrama na vida.

Rancière (2014, p.52) ao comentar essa nova configuração estética a define como "sem medida da mistura":

Assim a perda de medida comum entre os meios das artes não significa que daí em diante cada qual fique no seu compartimento, outorgando-se sua própria medida. Isso quer dizer sobretudo que toda a medida comum doravante é uma produção singular, e que essa produção é possível somente à custa de afrontar, na sua radicalidade, o sem medida da mistura. 
Adeus, cavalo, como outras obras de Nuno Ramos, e servindo-se dessa montagem da qual fala Rancière, poderia ser definida como uma prática do não pertencimento, sem com isso negativizar a saída do cânone, nem isso definir uma hierarquia ou um juízo de valor. Ainda assim, vale a pena fazer uma ressalva. A formulação de "prática do não pertencimento" seria só uma forma de abordagem inicial dessas novas produções artísticas, pois como dito antes, é necessário, em segunda instância, ver que tipo de contradiscurso essas obras híbridas são capazes de produzir com base no conjunto de escolhas e procedimentos estéticos adotados, e que contribuem para essa inespecificidade.

Assim, Florencia Garramuño (2014, p. 28) comenta o valor ativo da inespecificidade, que é o que se gostaria de recuperar aqui:

Désappartenance ou disblonging, em inglês, conservam um sentido mais ativo que negativo que eu gostaria de manter para essas práticas; um modo que, mais que exibir uma carência, faz da invenção do comum e desindividualizante uma proposta ativa para imaginar mundos alternativos, que talvez a palavra impertinência permita sugerir com mais facilidade.

O fracasso, o fragmento, articulam-se na ideia de incompletude e de híbrido. O próprio autor escreve em outro livro que precisa "encontrar a fração correta de fracasso", pois "estar em dia consigo é uma forma de avareza" (RAmos, 1993, p. 25), indicando de alguma maneira que os textos heterogêneos e as instalações híbridas poderiam ser essa busca do fracasso, da quebra da unidade. $\mathrm{O}$ autor em várias ocasiões confirma essa sua tendência em trabalhar com noções movediças, que ele mesmo definirá com a expressão "forma fraca", ${ }^{10}$ entendendo-a como um piso que constantemente desmorona em baixo dos seus pés, ou como uma goma que se estica e se compacta, preste a se tornar qualquer coisa ou nada. Essa ideia parece sinalizar um trabalho de experimentação das potencialidades da matéria e da linguagem, como para testá-las e ver até que ponto elas podem ser esticadas.

No que concerne às potencialidades da matéria poder-se-ia pensar nas fusões, deslizes e transformações; já no que tange à linguagem é possível pensar nas experimentações estilísticas, na junção de tipologias textuais e na variedade de tópicos abordados dentro do mesmo livro. Essa noção de forma fraca parece lembrar com outras palavras a ideia de devir da literatura de Deleuze (2011, p. 11): "A literatura está antes do lado do informe, ou inacabamento".

1o O autor em entrevista a Rodrigo Naves em 2011 afirmou trabalhar com uma "noção de forma fraca”, conceito que será retomado e tratado de forma extensa por Julia Studart (2014) na coleção Ciranda da poesia, Nuno Ramos por Júlia Studart. 


\section{Performance e voz}

[...] nós nunca recitávamos nada, principalmente isso, nunca memorizávamos nada, criávamos [...]. As palavras saltavam das portas e gavetas dos armários empenados pedindo voz, um Ibsen embolorado nas pregas daquelas cortinas de filme de terror, nas manchas dos lençóis (RAMOS, 2017, p. 57).

Essa citação abre emblematicamente este parágrafo, em que se tentará investigar um pouco mais a ideia de performance através da presença da voz. As palavras, verdadeiros seres ontológicos, têm vida própria a ponto de saltar das gavetas e pedir vida através da voz. O grafema contra o sopro, a escrita contra a fala, a ideia de passividade contra a ideia de atividade. A escrita ganha vida só quando um leitor pronuncia aquelas palavras, mesmo quando em leitura silenciosa, a mente processa aquela sequência de grafemas como som: "a leitura do texto poético é escuta de uma voz" (ZumTHOR, 2007, [1990], p. 87). Na citação acima, o ator entrevistado, lembrando os momentos da juventude, reivindica a plena performatividade dos atos artísticos que cumpriam, aquele famoso "aqui" e "agora" que Barthes (2015) reivindica para o ato de leitura. A linguagem enquanto viva não pode ser reprodução de outra fala já pronunciada, e até se houver correspondência de sequências lexicais e sintáticas, a sua textura será sempre outra, pois essa sequência se articula em outros corpos e outras vozes e dentro de outros contextos.

Nuno Ramos, em entrevista inédita, diz que, a partir da exposição das "série falas" - entre elas "Carolina" (2006) e "Ai de mim!" (2006) - ele tem se dado conta de que é como se sua poética estivesse vivendo uma passagem, uma metamorfose do peso da matéria para a leveza da voz, a qual também tem uma materialidade sua; o sopro que articula as palavras movimenta o ar e pede espaço. A voz, portanto, tem uma physis que lhe é própria e nesse contexto vem reforçar a ideia de linguagem viva, já que age diretamente sobre os corpos-leitores ativando os sentidos no processo de significação da obra. A voz em Adeus, cavalo é presença em duplo sentido:

- porque pode ser tratada a partir da sua textura e de suas maneiras de se propagar, das suas propriedades sonoras. Assim, o autor escreve no capítulo sete:

Um macaco que contava sua história a uma academia de ciência. Falava intercalando pequenos guinchos, alongando as vogais ou ressaltando fortemente as consoantes, mas sem tornar as palavras incompreensiveis. O Estertor de seus grunhidos parecia um desvio quase insignificante à nossa voz e pronúncia diárias. Nós, os pagantes. Os três pagantes (RAmos, 2017, p. 25). 
- porque desdobra-se nos numerosos corpos (as personagens) que a articulam, assim como descrito no capítulo 4:

A técnica do ator é a da memória feita cavalo - no sentido galope do termo, quando o animal reconhece caminho de casa depois de um longo passeio. É a técnica da fuga transferida à glote, à narina, às partes externas do grande fole. A soma das vozes fugindo em distorções da garganta, matizes agudos e graves, trajetos sutis, pigarros. No entanto, olhando para trás, reparando bem, é possível perceber os pequenos sinais que deixou enquanto fugia. Suas pegadas (RAMOs, 2017, p. 18).

Ao falar de um texto performático, estaremos de alguma maneira invocando o corpo. As narinas e a glote são chamadas a realizar essa identificação corporal dos lugares onde o som é articulado. E, como diz Zumthor (2007, p. 39), ${ }^{11}$ a ideia de performance envolve teatralidade e, portanto, espaço além de corpo. Esse corpo invocado é índice de uma relação do "eu ao ser físico" (Zuмthor, 2007, p. 39). Performance, espaço, corpo e voz se conectam inextricavelmente, segundo o autor, à ideia de teatralidade, tanto que o texto de Nuno Ramos, antes do complexo se entrecruzar das vozes que se alternam, abre o primeiro capítulo exatamente com uma cena do ator em exibição no palco, como que para situar de imediato o leitor diante ou dentro de uma peça:

Darei a entrevista em cena, pronunciou gravemente (...)

O silêncio prolongado em seguida à frase, dita de modo pausado e grave, pesou sobre todos.

Pronunciou a última palavra que diria naquela noite - Obrigado. (...) Com as luzes ainda apagadas, uma plateia incrivelmente dócil arrastou-se para fora no mais perfeito silêncio (RAMOS, 2017, p. 7-9).

O ator decide conceder a entrevista em cena, e é a partir daí que as incorporações das vozes acontecem, o efeito de teatralidade aqui se manifesta sem envolver necessariamente corpos empíricos, feitos de carne, ela existe a partir do momento em que é recriado o espaço virtual para a presença do outro que escutará.

A tal propósito, Zumthor fala em "audição performativa", toda a situação, até virtual, de escuta possibilita a criação de um espaço para a alteridade. Mas qual

"1 A noção de performance, encontraremos sempre um elemento irredutível, a ideia da presença de um corpo. Recorrer à noção de performance implica então a necessidade de reintroduzir a consideração do corpo no estudo da obra. Ora, o corpo (que existe enquanto relação, a cada momento recriado, do eu ao ser físico) é da ordem do indizivelmente pessoal. A noção de performance (quando os elementos se cristalizam em torno da lembrança de uma presença) perde toda pertinência desde que a façamos abarcar outra coisa que não o comprometimento empírico, agora neste momento, da integridade de um ser particular numa situação dada (ZuMTHOR, 2007 p. 39). 
seria essa alteridade para a qual o ator do livro fala? Trata-se dos leitores que se tornam também auscultadores. Dizer logo no início que dará a entrevista em cena contribui para criar uma situação de espera auditiva: cria-se um espaço para a performance. Assim Josette Féral entenderia esse conceito (FÉrAl apud Zumthor, 2017, p. 42) no qual se identifica a situação acima:

[...] cria o espaço virtual do outro: o espaço transicional de que falava Winncott. Isto é dizer que a teatralidade não tem manifestações físicas obrigatórias. Ela não tem propriedades qualitativas que permitiriam demarcá-la de vez. Ela não é um dado empírico, ela é uma colocação em cena do sujeito em relação ao mundo e a seu imaginário.

A teatralidade não é um dado empírico, mas a criação de uma circunstância na qual entram a corporeidade como sensação, os sentidos como percepção, a ideia de que há alguma alteridade falando e alguma alteridade escutando; o uso da voz para marcar a presença romperia com a "clausura do corpo" (ZumThoR, 2017, p. 83-84).

Quem de fato são essas vozes que se multiplicam em Adeus, cavalo? Ao percebermos a voz, segundo o autor suíço, estabelece-se "uma relação de alteridade que funda a palavra do sujeito", a palavra do outro torna-se por algum momento a minha palavra, pois a escuta precisa do meu silêncio, da atenção do meu corpo, e essa escuta dentro dessa leitura requer mais uma vez um leitor ativo. A voz do ator, a sinceridade de Procópio, a simplicidade de Nelson Cavaquinho, as reflexões de Ungaretti e as multidões de coros são no fundo as nossas vozes; afinal, através da leitura, eles falam por nós, como coloca Zumthor:

Sexta tese: escutar o outro é ouvir, no silêncio de si mesmo, sua voz que vem de outra parte. Essa voz, dirigindo-se a mim, exige de mim uma atenção que se torna meu lugar, pelo tempo dessa escuta. Essas palavras não definiriam igualmente bem o fato poético? (ZuмthoR, 2017, p. 84).

Antes de Adeus, cavalo o movimento da matéria fixado na escrita era a forma que o autor tinha de entender a voz, ou seja, a voz da matéria era o que realmente importava. Ela se expressava através da captação das transformações e das reconfigurações dos materiais. Assim, Nuno Ramos escreve nesse trecho de $O$ (2008):

Depois que passa pelas minhas mãos nada parece meu, minha tarefa: dar à voz a matéria - tinta, pano -, dar a matéria a sua voz, não por medo de perdê-la, ao contrário só me interessa o que teve força, caráter, para se perder de mim (há um ó guardado aí), não tranco afetos, cheiros, memória (RAmos, 2008, p. 155)

Em Adeus, cavalo a mudança da poética de Nuno Ramos da matéria para o sopro, desloca algumas linhas de tendência presentes nos livros iniciais, pois a voz é 
protagonista enquanto voz e não enquanto expressão da matéria. O peso e a consistência das texturas são liberados para deixar espaço à leveza do sopro, e o teatro e a atuação configuram-se como a melhor forma para encarnar essa passagem.

\section{Algumas observações finais}

Propõem-se algumas observações e considerações em forma de tópicos breves acerca das reflexões que marcaram os parágrafos anteriores e nortearam o ato de leitura de Adeus, cavalo.

Esse ato de leitura baseou-se:

- na reivindicação da prática da leitura como energheia, força em ação;

- na experimentação da linguagem como forma de vida, que ela não pode ser enclausurada em uma função representativa, sensível ou extrassensível que seja.

E configurou-se como:

- uma nova assinatura do texto; já que o autor não é imanente à sua escrita e tampouco a interpretação crítica cristalizada.

Portanto, aceitou que:

- onde há vida, há defasagem, deferibilidade, fracasso e imperfeição, consequentemente as categorias interpretativas clássicas binárias, cartesianas e subjetivistas caem; o híbrido, o heterogêneo e a experimentação fogem de qualquer categorização.

Por fim, observou que:

- Adeus, cavalo aparece como exemplo de aplicação de procedimento estético que envolve uma nova forma de montagem, associável ao conceito de fraseimagem, e encarna a linguagem como forma de vida: o texto é pura performance;

- a performance envolve espaço, corpo e voz, e esses três não são entendidos necessariamente empiricamente, mas sim como criação de circunstâncias geradoras de sensações e percepções; de modo que uma situação de recriação de audição performativa permeia o texto Adeus, cavalo;

- a voz geralmente acompanha a performance, ela pode ser o lugar da alteridade; o silêncio do leitor recebe uma voz que o habita, essa voz do texto torna-se a sua própria voz, e ao mesmo tempo, é reconhecimento da voz do outro.

Essas considerações longe de serem axiomas assertivos, visam ser apenas um ponto de partida para repensar e refletir sobre a prática da leitura reconsiderando 
a ideia de interpretação como uma nova relação entre mente e percepção que o leitor vivencia ao se aproximar do texto. Para que essa relação seja renovada é preciso renunciar a algumas práticas interpretativas cristalizadas e desistir da vontade de uma suposta verdade fundadora do texto.

\section{Referências}

Agamben, Giorgio. O fim do poema. Tradução de Sérgio Alcides. Cacto, n. 1, São Paulo, 2002. p. 143-149.

Barthes, Roland. Le Bruissement de la langue. Essais Critique IV. Normandie: Èditions du Seuil, 2015.

Culler, Jonathan. Em defesa da superinterpretação. In: Eco, Umberto. Interpretação e Superinterpretação. São Paulo: Martins Fontes, 1993.

Derrida, Jacques. Mal de Arquivo. Uma impressão freudiana. Tradução de Claudia de Moaraes Rego. Rio de Janeiro: Relume Dumará, 2001.

Eco, Umberto. Superinterpretando textos. In: Interpretação e superinterpretação. São Paulo, Martins Fontes, 1993. p. 53 -77.

Foucault, Michel. As palavras e as coisas: uma arqueologia das ciências humanas. Tradução de Salma Tannus Muchail. São Paulo: Martins Fontes, 2016.

Foucault, Michel. A ordem do discurso. Tradução de Laura Fraga de Almeida Sampaio. São Paulo: Edições Loyola, 2016.

Garramuño, Florencia. Frutos estranhos: sobre a inespecificidade na estética contemporânea. Rio de Janeiro: Rocco, 2014.

Martins, Helena. Três caminhos na filosofia da linguagem. In: Mussalim, F.; BenTES, A.C. Introdução à linguística. Vol. 3 Fundamentos epistemológicos. São Paulo: Corf, 2001. p. 448-474.

NAncy, Jean- Luc. Fazer, a poesia. Tradução de Letícia D. G. de França, Janaina Ravagno ni, Mauricio Mendonça Cardozo, Alea, Rio de Janeiro, vol. 15 n. 2, p. 414422, jul./dez. 2013 .

Ramos, Nuno. Adeus, Cavalo. São Paulo: Iluminuras, 2017.

Ramos, Nuno. Cujo. São Paulo: Editora 34, 2011.

RAmos, Nuno. Ó. São Paulo: Iluminuras, 2008.

RANCIÈre, Jacques. O destino das imagens. Tradução Monica Costa Netto. Rio de Janeiro: Contraponto, 2014.

RoRTy, Richard. A trajetória do pragmatista. In: Eco, Umberto. Interpretação e Superinterpretação. São Paulo: Martins Fontes, 1997. p. 105-127. 
Sontag, Susan. Contra a interpretação. Tradução de Ana Maria Capovila. Porto Alegre: L\&PM, 1987.

Speranza, Graciela. Atlas portátil de América Latina. Arte y ficciones errantes. Barcelona: Anagrama, 2012.

Studart, Julia. Ciranda da poesia, Nuno Ramos por fúlia Studart. Rio de Janeiro: edUerj, 2014.

Zumthor, Paul. Performance, recepção, leitura. Tradução Jerusa Pires Ferreira e Suely Fenerich. São Paulo: Cosac Naify, 2007.

\section{Catálogo de consulta das obras do autor}

Ramos, Nuno. Nuno Ramos. Catálogo. Rio de Janeiro: Cobogó, 2010.

\section{Entrevista}

Rodrigo Naves. Transformar a desmesura em liberdade [novembro 2011]. Nuno Ramos. Disponível em: http://www.nunoramos.com.br/portu/depo2.asp?flg_ Lingua $=1 \&$ cod_Depoimento=36. Acesso em: 09 dez. 2017 .

Recebido em o7 de julho de 2018.

Aprovado em 26 de fevereiro de 2018.

\section{Resumo/Abstract/Resumen}

Adeus, cavalo, de Nuno Ramos: quando o corpo vibra e o texto estremece um ato de leitura

\section{Irma Caputo}

O presente artigo visa acompanhar de forma analítica o processo de um ato de leitura pessoal de uma produção literária brasileira contemporânea, Adeus, cavalo (2017), do escritor e artista plástico Nuno Ramos. Serão definidas as linhas norteadoras que guiarão o presente ato de leitura por meio do questionamento da ideia de paternidade da obra, crítica literária institucionalizada e leitura como interpretação hermenêutica. A uma ideia de linguagem como representação binária será contraposta a ideia de linguagem como forma de vida, visão consequentemente acompanhada por uma de leitura como energheia, força em ação que faz da experiência do corpo leitor a base de significação do texto, também partindo e considerando a natureza performática do texto escolhido. 
Palavras-chave: Nuno Ramos, Adeus, cavalo, literatura e performance, leitura, teoria da recepção.

Adeus, cavalo, by Nuno Ramos: When the Body Vibrates and the Text Pulsates in the Act of Reading

\section{Irma Caputo}

This article aims to follow analytically the process of an act of personal reading of a contemporary Brazilian literary work, Adeus, cavalo (2017), by writer and visual artist Nuno Ramos. The guiding lines that will lead the present reading act will be defined through the questioning of the idea of paternity of the work, institutionalized literary criticism and reading as hermeneutic interpretation. The idea of language as a binary representation will be contrasted with the idea of language as a way of life, a vision consequently accompanied by one of reading as energy, a force in action which takes the experience of the reading body as the basis for the signification of the text, which is also due to the performative nature of the chosen text.

Keywords: Nuno Ramos, Adeus, cavalo, literature and performance, reading, reception theory.

\section{Adeus, cavalo, de Nuno Ramos: cuando el cuerpo vibra y el texto se estre- mece en un acto de lectura}

\section{Irma Caputo}

Este artículo pretende acompañar de forma analítica el proceso de un acto de lectura personal de una producción literaria brasileña contemporánea: Adeus, cavalo (2017), del escritor y artista plástico Nuno Ramos. Se definirán las líneas orientadoras que guiarán el acto de lectura a través del cuestionamiento de conceptos como: paternidad de la obra, crítica literaria institucionalizada y lectura como interpretación hermenéutica. A una idea del lenguaje como representación binaria se contrapone la idea del lenguaje como forma de vida; visión consecuentemente acompañada por una lectura como energheia, fuerza en acción que hace de la experiencia del cuerpo lector la base de significación del texto, debido también a la naturaleza performática del texto escogido.

Palabras clave: Nuno Ramos, Adeus, cavalo, literatura y performance, lectura, teoría de la recepción. 